\title{
The prognostic significance of intranodal isolated tumor cells and micrometastases in patients with non-small cell carcinoma of the lung
}

\author{
Alberto M. Marchevsky, MD \\ Jian-Huan Qiao, MD ${ }^{\mathrm{a}}$ \\ Sanja Krajisnik, MD \\ James M. Mirocha, $\mathrm{MS}^{\mathrm{b}}$ \\ Robert J. McKenna, MD ${ }^{c}$
}

See related editorial on page 332.
From the Departments of Pathology and Laboratory Medicine, ${ }^{\mathrm{a}}$ Biostatistics, ${ }^{\mathrm{b}}$ and Thoracic Surgery, ${ }^{\mathrm{c}}$ Cedars-Sinai Medical Center, Los Angeles, Calif.

Received for publication July 15, 2002; revisions requested Aug 19, 2002; revisions received Oct. 2, 2002; accepted for publication Oct 18, 2002.

Address for reprints: Alberto M. Marchevsky, MD, Cedars-Sinai Medical Center, 8700 Beverly Blvd, Los Angeles, CA 90048 (E-mail: alberto.marchevsky@ cshs.org).

J Thorac Cardiovasc Surg 2003;126:551-7

Copyright $\odot 2003$ by The American Association for Thoracic Surgery

$0022-5223 / 2003 \$ 30.00+0$

doi:10.1016/S0022-5223(03)00123-5
Objective: To study whether isolated tumor cells and micrometastases, as defined by the current American Joint Committee on Cancer criteria for extrapulmonary neoplasms, have prognostic value for patients with resected non-small cell carcinoma of the lung.

Methods: Intrathoracic lymph nodes $(n=1063)$ from 60 patients with non-small cell carcinoma of the lung were studied for the presence of metastases with serial histologic sections and keratin immunostains. Metastases were classified as isolated tumor cells, $\mathrm{pN} 1 \mathrm{mi}, \mathrm{pN} 1, \mathrm{pN} 2 \mathrm{mi}$, and $\mathrm{pN} 2$. Isolated tumor cells were smaller than $0.2 \mathrm{~mm}$, while $\mathrm{pN} 1 \mathrm{mi}$ and $\mathrm{pN} 2 \mathrm{mi}$ measured $0.2 \mathrm{~mm}$ to $2 \mathrm{~mm}$. Survival analysis was performed, stratifying by nodal status and stage.

Results: Isolated tumor cells were detected in 11 lymph nodes from 5 of 33 pN0 patients and in $9 \mathrm{pN} 1$ and $\mathrm{pN} 2$ patients. The lymph nodes from 3 patients were reclassified as pN1mi. No pN2mi were detected. A survival model based on a stratification of the cohort into stages I to III was significant (chi-square $=7.426$, df $=2, P=.024$ ) but demonstrated considerable overlap between the survival curves of stage I and II patients. A model stratifying isolated tumor cells and pN1mi into stage I disease was significant (chi-square $=7.985, \mathrm{df}=2, P=.018$ ) and showed no overlap between the survival curves of stage I and II patients. There were no significant survival function differences between patients with $\mathrm{pN}$, isolated tumor cells, and pN1mi.

Conclusions: Patients with non-small cell carcinoma of the lung with isolated tumor cells and $\mathrm{pN} 1 \mathrm{mi}$ have similar survivals to those with $\mathrm{pN} 0$, consistent with the findings reported for breast cancer patients. Future larger studies of patients with non-small cell carcinoma of the lung are needed to confirm whether current American Joint Committee on Cancer staging criteria should be modified to include the $\mathrm{pN} 1 \mathrm{mi}$ category.

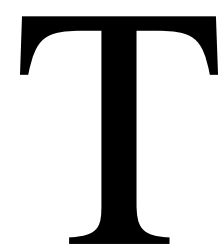

he American Joint Committee on Cancer (AJCC) has recently published the sixth edition of the AJCC Cancer Staging Manual, including revised staging criteria for breast, colon, and other neoplasms. ${ }^{1}$ Staging criteria for lung cancer remain unchanged. The evaluation of the lymph node status of patients with non-small cell lung cancer (NSCLC) has been a source of controversy.,3 Lymph node metastases can be subclassified into intranodal growth when the tumor is confined within the lymph node capsule and extranodal growth when there is neoplastic invasion of the soft tissues surrounding the nodal tissues. However, as demonstrated by Bollen and associates, ${ }^{4}$ it is seldom feasible to classify, on the basis of mediastinoscopy, a 
lymph node involvement as intranodal or extranodal, as portions of each lymph node rather than the entire intact lymph nodes are biopsied. This feature is not used for the routine staging of NSCLC patients or included in the current AJCC criteria for lung cancer.

Several studies have detected keratin-immunoreactive tumor cells in up to $63 \%$ of intrathoracic lymph nodes from NSCLC patients. ${ }^{5-10}$ The prognostic value of detecting these "occult metastases" or "micrometastases" in lung cancer and other neoplasms is the subject of intense research. ${ }^{5,11-18}$ Cote and associates ${ }^{3,19-22}$ indicated that "the accumulated evidence strongly suggests that the detection of occult regional and systemic metastases is an important predictor of disease progression." In a more recent study of 119 patients with T1, N0, and M0 adenocarcinoma and bronchioloalveolar carcinoma of the lung, Goldstein and associates ${ }^{12}$ reported "micrometastases" detectable by keratin immunohistochemistry in up to $8 \%$ of $\mathrm{N} 0$ patients. However, the overall sensitivity of the method was low, and positive cells were detected in only $0.5 \%$ to $1 \%$ of the lymph nodes examined. In one of their groups of patients who developed metastatic disease, the finding of micrometastases was significant for prognosis by multivariate analysis, but the authors concluded that due to the low sensitivity of the detection method, the use of immunohistochemical screening of lymph nodes for all N0 patients is questionable. Their study also confirmed the prognostic value of pathologic features such as vascular invasion, extensive central fibrosis, and high nuclear grade. Similar problems have been reported in studies of patients with esophageal, breast, and other neoplasms. ${ }^{5,11,14,23-27}$

The new AJCC Cancer Staging Manual proposes improved terminology for the classification of lymph node metastases. Isolated tumor cells (ITC) are defined as single tumor cells or small clusters of cells, smaller than $0.2 \mathrm{~mm}$ in greatest diameter. ${ }^{1}$ ITC can be seen on routine hematoxylin and eosin (H\&E) stained sections (pNOi-, pNOmol-) or detected with the aid of immunohistochemistry (pNOi+) or molecular methods (pNOmol+). Micrometastases are clusters of tumor cells measuring between $0.2 \mathrm{~mm}$ and $2 \mathrm{~mm}$ in greatest diameter; they can usually be detected with routine histology and are classified as pN1mi or pN2mi according to their location. However, according to current AJCC criteria for lung cancer, NSCLC patients with a few intranodal tumor cells detected by routine histology or immunohistochemistry should be categorized as $\mathrm{pN} 1$ or $\mathrm{pN} 2$ according to their location. To our knowledge, it is unclear whether these patients have a similar prognosis as those with larger nodal metastases. We studied the prognostic value of detecting ITC in intrathoracic lymph nodes and distinguishing pN1mi and $\mathrm{pN} 2 \mathrm{mi}$ from $\mathrm{pN} 1$ and $\mathrm{pN} 2$ in a group of 60 consecutive NSCLC patients who had long-term clinical follow-up.

\section{Methods}

NSCLC patients treated with lobectomy at Cedars-Sinai Medical Center during an arbitrarily selected 2-year period (July 1993 to June 1995) were studied. Sixty consecutive patients had adequate clinical follow-up information available at our Tumor Registry. Our Institutional Review Board approved the study and proper informed consent guidelines were followed. Patients who survived the disease had a minimum 5-year clinical follow-up after the initial treatment. The cohort included 37 women and 23 male patients, ranging in age from 37 to 94 years $(66.72 \pm 12.42$ years). NSCLC cell types included adenocarcinoma $(n=37)$, squamous cell carcinoma $(\mathrm{n}=10)$, adenosquamous carcinoma $(\mathrm{n}=9)$, and large cell carcinoma $(\mathrm{n}=4)$. Tumors ranged in size from $1.6 \mathrm{~cm}$ to $10 \mathrm{~cm}$ in greatest dimension $(4.11 \pm 1.53 \mathrm{~cm})$. The pT information of the neoplasms included: pT1 $=19, \mathrm{pT} 2=32, \mathrm{pT} 3=3$, and pT $4=6$ cases. The initial nodal status of the 60 patients was: $\mathrm{pN} 0=33, \mathrm{pN} 1=11$, and $\mathrm{pN} 2=16$. The H\&E-stained histologic slides from 1063 formalin-fixed, paraffin-embedded intrathoracic lymph nodes from these patients were reviewed. Two serial sections, $4 \mu \mathrm{m}$ in thickness, were made from each lymph node at $50-\mu \mathrm{m}$ intervals and stained with H\&E. A third serial section from each lymph node was stained with immunohistochemistry for keratin AE1/AE3 (Chemicon Inc, Temecula, Calif), using a standard DAKO Envision peroxidase method (DAKO, Carpinteria, Calif). A working dilution of 1:2000 was used for the primary antibody. Our experience with NSCLC is similar to that of Cote and associates, ${ }^{19}$ who have demonstrated that keratin AE1 and CAM 5.2 yield similar results for the detection of lymph node metastases in breast cancer patients.

\section{Estimation of Nodal Status}

Based on the examination of the initial histologic slides, the initial nodal status of each patient was recorded. The lymph nodes were classified as pN0, pN1, and pN2 according to current AJCC criteria for NSCLC. The size of all lymph node metastases was measured with an eyepiece micrometer. The size of all metastases from the various lymph nodes from each patient was added to an aggregate tumor size per case and stratified into 3 categories: smaller than $0.2 \mathrm{~mm}, 0.2 \mathrm{~mm}$ to $2 \mathrm{~mm}$, and larger than $2 \mathrm{~mm}$. ITC detected in H\&E-stained serial histologic sections were classified as pNOi-. They consisted of single or small groups of cells with cytologic features including a nuclear size larger than the diameter of 3 resting mature lymphocytes, anisocytosis, macronucleoli, irregular nuclear membranes, and/or high nucleo:cytoplasmic ratio. Cells with cytoplasmic keratin immunoreactivity that exhibited similar cytologic features, visible with the aid of the nuclear counterstain, were classified as pNOi+. The $\mathrm{N}$ status of each case was reclassified into 6 ordered categories, using the terminology proposed in the sixth edition of the AJCC cancer staging manual for breast cancer and other neoplasms: pN0, ITC (including pNOi- and pNOi+), pN1mi, pN1, pN2mi, and pN2. Figures 1 and 2 show examples of isolated tumor cells and micrometastases.

\section{Statistical Analysis}

Survival functions were estimated using the Kaplan-Meier method. Survival functions were compared across current $\mathrm{N}$ criteria (pN0, $\mathrm{pN} 1$, and $\mathrm{pN} 2$ ) and enhanced criteria including ITC and $\mathrm{pN} 1 \mathrm{mi}$ as additional categories. Survival functions of pNO patients were 


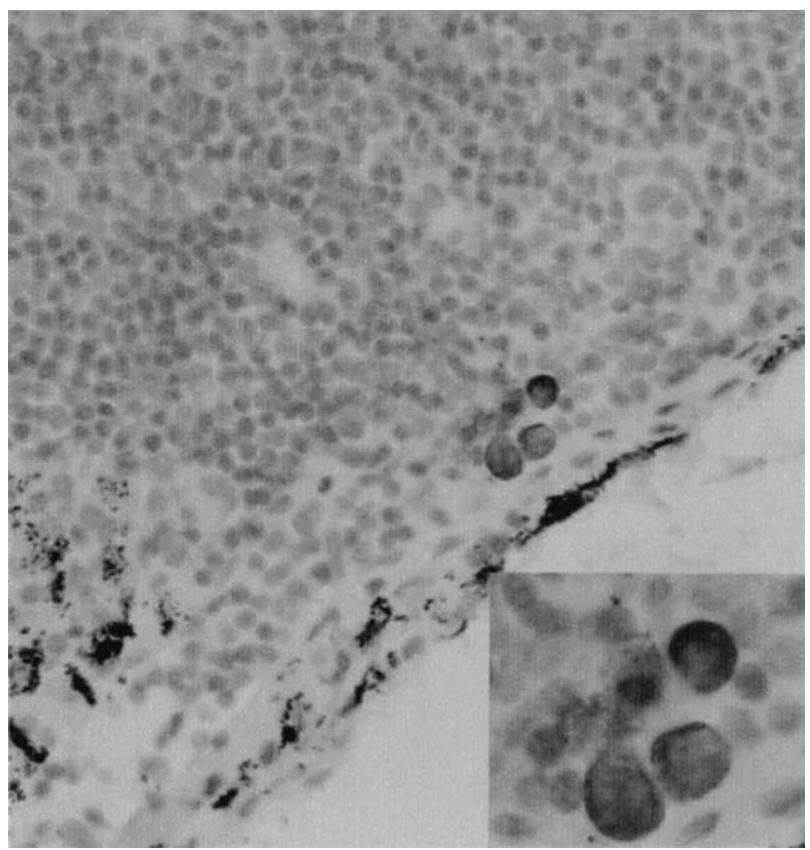

Figure 1. Photomicrograph of isolated tumor cells in a lymph node from a patient with adenocarcinoma of the lung (Dako Envision peroxidase method, $400 \times$ ). A few cells with cytoplasmic keratin immunoreactive are present near the subcapsular sinus of a lymph node. The inset shows that the cells have a size that is approximately 3 times the size of normal lymphocytes. A lymph node with these cells is classified as pNOi+ to indicate the presence of isolated tumor cells detectable with immunohistochemistry.

compared with those with ITC and pN1. Survival functions of patients with ITC and pN1mi were compared with those with pN1. Survival functions were also analyzed by stage, stratifying patients into stages I to III, and by a modified staging scheme that included patients with ITC or pN1 in the stage I group. Homogeneity of survival functions was analyzed using the log-rank test (Mantel method). Analyses were performed using Systat 10.0 software (SPSS Science, Chicago, Ill). Regression analysis was performed to compare the tumor size with the presence of isolated tumor cells in $\mathrm{pNO}$ patients.

\section{Results}

Nine hundred forty lymph nodes $(88.4 \%)$ were negative for metastatic tumor, and 123 lymph nodes $(11.6 \%)$ were positive by examination of the initial H\&E-stained slides. ITC were encountered with the aid of immunohistochemistry in 11 of 463 (2.4\%) lymph nodes originally classified as pN0; the same ITC were also visible by examination of H\&Estained step sections in 5 of those lymph nodes. Lymph nodes with pNOi- and pNOi+ were encountered in 5 of 33 (15.2\%) pN0 patients (Table 1). Regression analysis showed no significant relationship between tumor size and the presence of isolated tumor cells and/or micrometastases in $\mathrm{pN} 0$ patients $(\mathrm{df}=1, \mathrm{~F}=0.026, P=.87)$.

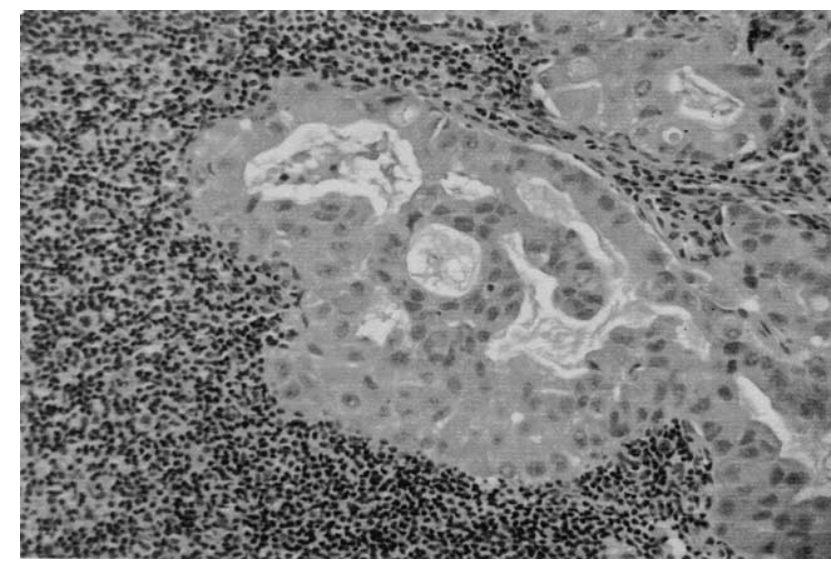

Figure 2. Photomicrograph of a lymph node with metastatic adenocarcinoma. The tumor nodule is smaller than $\mathbf{2} \mathbf{~ m m}$ in diameter, the cutoff diameter used for the diagnosis of micrometastases. A lymph node with these cells is classified as pN1mi.

TABLE I. Survival proportions of non-small cell carcinoma of the lung patients, by nodal status classified with different criteria $(n=60)$

\begin{tabular}{|c|c|c|c|}
\hline $\begin{array}{l}\text { Criteria for } \\
\text { classification of nodal } \\
\text { status }\end{array}$ & Nodal status & $\begin{array}{c}\text { Total number } \\
\text { of patients }\end{array}$ & $\begin{array}{c}\text { Number of } \\
\text { patients who } \\
\text { survived } 5 \text { years }\end{array}$ \\
\hline \multirow{2}{*}{$\begin{array}{l}\text { Current AJCC criteria } \\
\text { for lung cancer } \\
\text { patients }\end{array}$} & pNO & 33 & $21(63.6 \%)$ \\
\hline & $\begin{array}{l}\mathrm{pN} 1 \\
\mathrm{pN} 2\end{array}$ & $\begin{array}{l}11 \\
16\end{array}$ & $\begin{array}{l}5(45.4 \%) \\
3(18.8 \%)\end{array}$ \\
\hline \multirow{5}{*}{$\begin{array}{l}\text { AJCC criteria } \\
\text { proposed for } \\
\text { breast cancer and } \\
\text { other neoplasms }\end{array}$} & $\mathrm{pNO}$ & 28 & $18(64.3 \%)$ \\
\hline & $\begin{array}{l}\text { Isolated tumor } \\
\text { cells }\end{array}$ & 5 & $3(60 \%)$ \\
\hline & pN1mi & 3 & $3(100 \%)$ \\
\hline & pN1 & 8 & $2(25 \%)$ \\
\hline & pN2 & 16 & $3(18.8 \%)$ \\
\hline
\end{tabular}

In addition, ITC were encountered in 9 of 477 (1.9\%) previously negative lymph nodes from $\mathrm{pN} 1$ and $\mathrm{pN} 2$ cases. None of the pN1 patients were upstaged to $\mathrm{pN} 2$ as a result of encountering ITC. The lymph nodes from 3 of 11 (27.3\%) patients with pN1 nodal status by initial examination had metastases measuring $0.2 \mathrm{~mm}$ to $2 \mathrm{~mm}$ in greatest diameter and could be reclassified as $\mathrm{pN} 1 \mathrm{mi}$. All cases with pN2 had metastases larger than $2 \mathrm{~mm}$.

The proportions of patients who survived their disease, by nodal status, are shown in Table 1 . The survival proportions of pN0 cases $(63.6 \%)$ did not change after ITC cases 


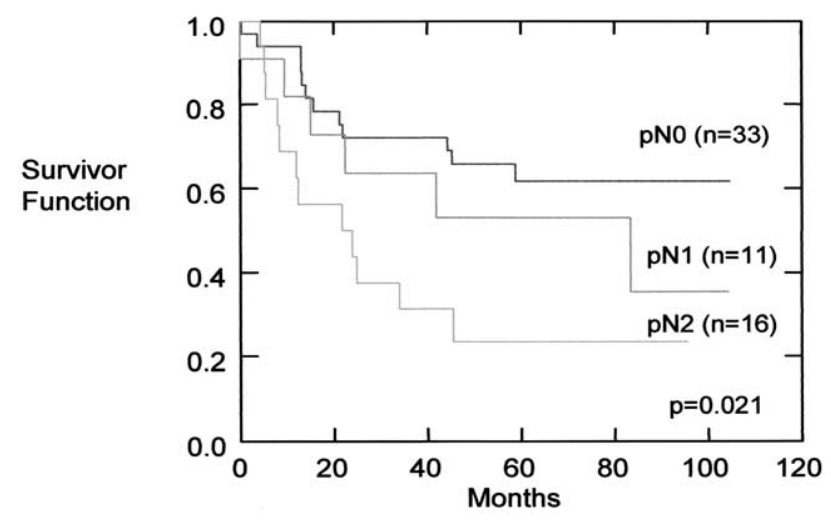

Figure 3. Survival analysis of all 60 patients showing significant stratification of the patients by the original nodal status.

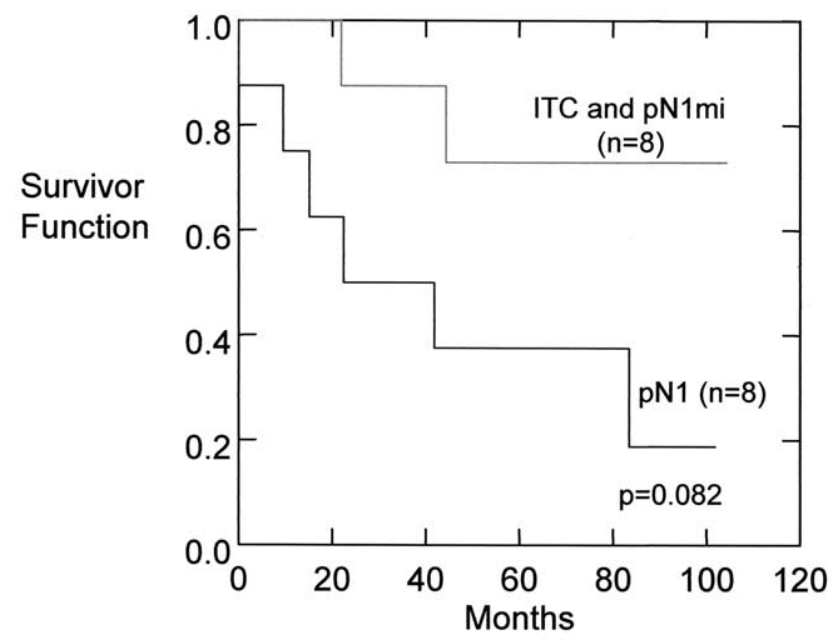

Figure 4. Survival analysis of a subgroup of 16 patients, showing apparent, but no significant differences in survivor function between patients with isolated tumor cells (ITC) and micrometastasis (pN1mi) from those with nodal metastases larger than $2 \mathrm{~mm}$ in size.

were removed from this group and reclassified as pNOi+ (64.3\%). The survival proportions of $\mathrm{pN} 1$ patients declined considerably from $45.4 \%$ to $25 \%$ after cases with micrometastases were removed from this group and reclassified as pN1mi. All 3 patients with pN1mi survived. Figure 3 shows significantly different survival curves by initial nodal status (chi-square $=7.744$, df $=2, P=.021$ ). There were no significant differences in the survival functions of $\mathrm{pNO}$ patients compared with those with ITC and pN1mi (chisquare $=0.001, \mathrm{df}=1, P=.975$ ). Figure 4 shows no significant differences in the survival functions of patients with $\mathrm{pNOi}+$ or $\mathrm{pN} 1 \mathrm{mi}$ compared with those with $\mathrm{pN} 1$ (chi-square $=3.028, \mathrm{df}=1, P=.082$ ). However, the graph shows 2 distinct survival curves and the lack of significant differences may result from the small sample size. Survival functions could not be compared across the $\mathrm{pN} 1$ and $\mathrm{pN} 1 \mathrm{mi}$ categories due to the small number of patients. Figure 5 shows different survival curves for patients stratified by stages I to III (chi-square $=7.426$, df $=2, P=.024$ ). However, this model shows some overlap between the survival curves of stage I and II patients. Figure 6 shows different survival curves by stage when cases with ITC and $\mathrm{pN} 1 \mathrm{mi}$ are classified as stage I disease (chi-square $=7.985$, $\mathrm{df}=2, P=.018$ ). This model shows a distinct survival curve for stage I disease and some overlap between the survival curves of stage II and III disease.

\section{Discussion}

Our preliminary study suggests that the current criteria proposed by the AJCC for the classification of the N status of various extrapulmonary neoplasms may also be useful for NSCLC patients. We detected ITC in $15.2 \%$ of pN0 NSCLC patients, but this finding did not influence the proportion of $\mathrm{pN} 0$ patients who survived their disease or their survival functions. Our results support the use of pNOi- and pNOi+, rather than $\mathrm{pN} 1$, terminology for patients with ITC until more data are available to justify staging them as stage II disease. Similar findings have been reported in studies of breast cancer and other neoplasms, leading to the development of the current pNOi, pNmi terminology supported by AJCC. ${ }^{1}$ Our data, based on a very small number of cases, also suggest that measuring the size of small lymph node metastases and classifying them into pN1mi, using the 2-mm cutoff value proposed by AJCC for other neoplasms, may have a prognostic value in NSCLC patients. Patients with pNOi+ and pN1mi had $60 \%$ and $100 \%$ survivals, respectively, compared with a $25 \%$ survival for patients with metastases larger than $2 \mathrm{~mm}$ in $\mathrm{pN} 1$ lymph nodes. Moreover, the survivals of patients initially classified as $\mathrm{pN} 1$ declined from $45.4 \%$ to $25 \%$ after the 3 cases with micrometastases were excluded. Survival analysis by stage, classifying NSCLC patients with ITC and pN1mi as stage I rather than stage II disease, yields a significant survival model and appears to provide distinct survival curves between stage I and others.

The study of lymph nodes with immunohistochemistry and the measurement of metastases did not contribute significant prognostic information to our $\mathrm{pN} 2$ patients. No instances of $\mathrm{pN} 2 \mathrm{mi}$ were encountered in our $16 \mathrm{pN} 2 \mathrm{pa}-$ tients, and none of our $11 \mathrm{pN} 1$ patients were upstaged as a result of these additional studies. These findings suggest that keratin immunohistochemistry is unlikely to be useful for the study of larger cohorts of $\mathrm{pN} 1$ and $\mathrm{pN} 2$ patients. Future studies with larger number of $\mathrm{pN} 1$ cases are needed to confirm the possible prognostic value of identifying pN1mi. 


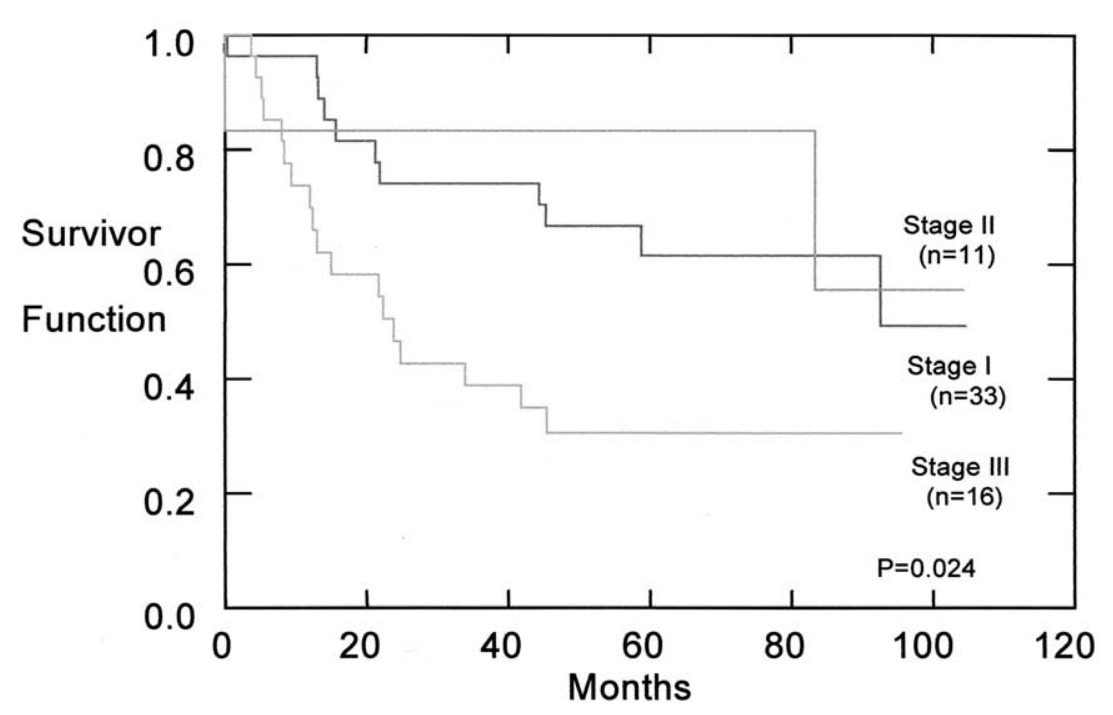

Figure 5. Survival analysis of all 60 patients by stage before correction of nodal status for the presence of micrometastases. The graph shows considerable overlap between the survival curves of patients in stages I and II.

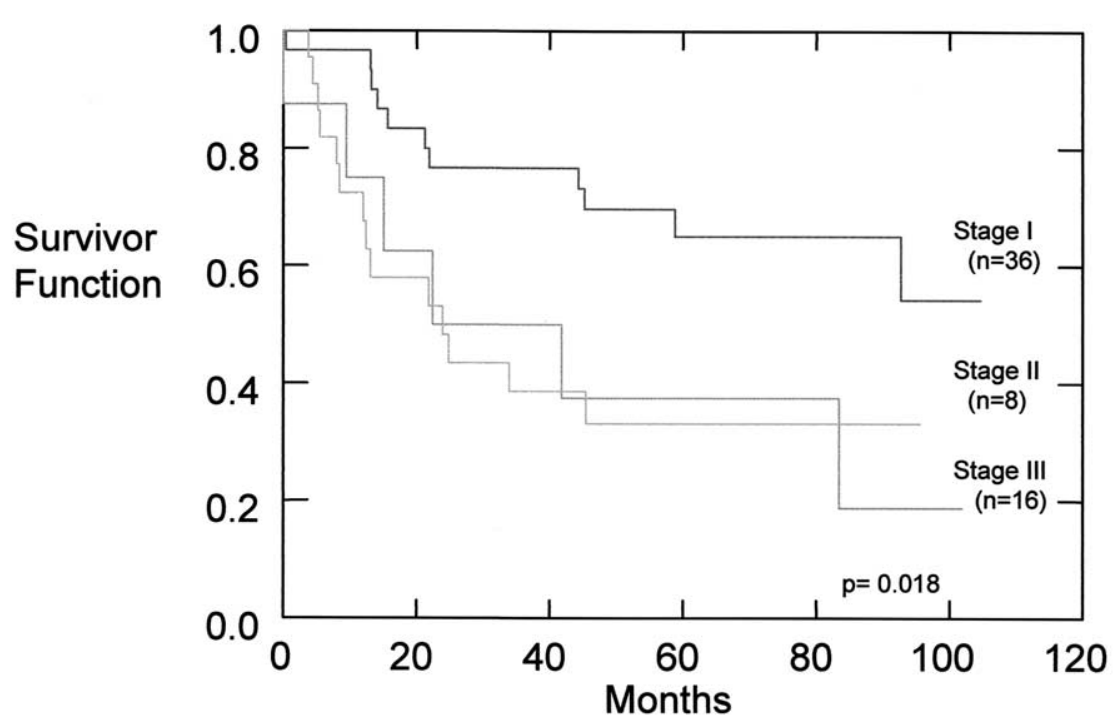

Figure 6. Survival analysis of all 60 patients after the stage was corrected by subtracting micrometastases from the pN1 category. The graph shows visually different curves for patients in stage I and II disease.

Our study raises questions regarding the practical role of immunohistochemistry for the study of lymph node metastases in patients with NSCLC. Several previous studies have reported that the finding of keratin immunoreactive tumor cells in approximately $4 \%$ to $63 \%$ of lymph nodes from NSCLC patients is usually associated with a less favorable prognosis. ${ }^{5-8,10,28,29}$ However, various definitions for "micrometastases" or "occult metastases" have been used; the size of the metastases has not always been reported and relatively small numbers of patients have been studied. ${ }^{30-32}$
Potential sources of variability include the study of only N0 patients by some investigators and of N0 to N3 by others and the use of different antibodies and/or immunohistochemical detection methods. ${ }^{12}$ Our data support the suggestion by Goldstein and associates ${ }^{12}$ that although ITC can be detected with immunohistochemistry in a significant number of previously negative lymph nodes, many of them are seen in NSCLC patients with other positive $\mathrm{pN} 1$ and $\mathrm{pN} 2$ lymph nodes. Slightly less than half of the lymph nodes with immunoreactive ITC encountered in our study were de- 
tected in the negative lymph nodes from patients with other positive $\mathrm{pN} 1$ and $\mathrm{pN} 2$ lymph nodes; the stage of these patients remained unchanged.

The influence of the size of intranodal metastases on the prognosis of NSCLC patients has not been studied extensively, to our knowledge. Bollen and associates ${ }^{4}$ demonstrated that NSCLC patients with "minimal disease," characterized by the presence of a single, small metastatic focus, had significantly better survival rates than N2 patients with more extensive nodal involvement.

Molecular methods may offer a more sensitive and costeffective method for the detection of occult micrometastases in the future, but it is unclear if these findings are going to provide prognostic information for NSCLC patients. Salerno and associates ${ }^{18}$ demonstrated the presence of MUC1 RNA in histologically negative lymph nodes from NSCLC patients, using reverse-transcriptase-polymerase chain reaction. Recently D'Amico and colleagues ${ }^{33,34}$ and Ahrendt and coworkers ${ }^{35}$ have applied molecular methods to the assessment of lymph nodes in patients with resected stage I NSCLC. Occult lymph node metastases identified based on the presence of p53 and k-Ras mutations are found in up to $50 \%$ of patients but do not correlate with overall survival. ${ }^{35}$ D'Amico and colleagues ${ }^{33,34}$ have demonstrated that expression levels of markers such as p53, urokinase plasminogen activator, E-cadherin, and ErbB2 correlated with the rate of brain metastases.

It is premature to speculate how stage I and II NSCLC patients will be managed in the future based on the detection of micrometastatic disease, as current postoperative therapeutic modalities are not very effective. To our knowledge, breast cancer patients with micrometastases are currently not being treated with chemotherapy, although this option is offered to $\mathrm{pN} 1$ patients. ${ }^{19}$

In conclusion, NSCLC patients with ITC and pN1mi have similar survival rates as those with $\mathrm{pN}$, results that are consistent with those already reported for breast cancer and other cancer patients. Lymph nodes with ITC should probably not be classified as $\mathrm{pN} 1$ until future studies demonstrate a clear prognostic value for this finding. Larger groups of NSCLC patients with stage II disease need to be studied for the distinction of $\mathrm{pN} 1 \mathrm{mi}$ versus $\mathrm{pN} 1$ to determine whether current AJCC staging criteria for NSCLC patients need to be modified.

The authors thank Dr Randa Alsabeh for assistance in the performance of immunostains and the selection of cases.

\section{References}

1. American Joint Committee on Cancer. AJCC cancer staging manual. 6th ed. New York: Springer; 2002.

2. Hawes D, Neville AM, Cote RJ. Occult metastasis. Biomed Pharmacother. 2001;55:229-42.

3. Cote RJ, Hawes D, Chaiwun B, Beattie EJ Jr. Detection of occult metastases in lung carcinomas: progress and implications for lung cancer staging. J Surg Oncol Suppl. 1998;69:265-74.

4. Bollen EC, Theunissen PH, van Duin CJ, Drenth BM, van Noord JA, Blijham GH. Clinical significance of intranodal and extranodal growth in lymph node metastases of non-small cell lung cancer. Scand J Thorac Cardiovasc Surg. 1994;28:97-102.

5. Chen ZL, Perez S, Holmes EC, et al. Frequency and distribution of occult micrometastases in lymph nodes of patients with non-small-cell lung carcinoma. J Natl Cancer Inst. 1993;85:493-8.

6. Yabushita H, Shimazu M, Yamada H, et al. Occult lymph node metastases detected by cytokeratin immunohistochemistry predict recurrence in node-negative endometrial cancer. Gynecol Oncol. 2001; 80:139-44.

7. Sasaki M, Watanabe H, Jass JR, et al. Occult lymph node metastases detected by cytokeratin immunohistochemistry predict recurrence in "node-negative" colorectal cancer. J Gastroenterol. 1997;32:758-64.

8. Gu CD, Osaki T, Oyama T, et al. Detection of micrometastatic tumor cells in pN0 lymph nodes of patients with completely resected nonsmall cell lung cancer: impact on recurrence and survival. Ann Surg. 2002;235:133-9.

9. Passlick B, Kubuschok B, Izbicki JR, Thetter O, Pantel K. Isolated tumor cells in bone marrow predict reduced survival in node-negative non-small cell lung cancer. Ann Thorac Surg. 1999;68:2053-8.

10. Maruyama R, Sugio K, Mitsudomi T, Saitoh G, Ishida T, Sugimachi $K$. Relationship between early recurrence and micrometastases in the lymph nodes of patients with stage I non-small-cell lung cancer. J Thorac Cardiovasc Surg. 1997;114:535-43.

11. Okada YF. Genetic detection of lymph node micrometastases in patients with gastric carcinoma by multiple-marker reverse transcriptasepolymerase chain reaction assay. Cancer. 2001;92:2056-64.

12. Goldstein NS, Mani A, Chmielewski G, Welsh R, Pursel S. Immunohistochemically detected micrometastases in peribronchial and mediastinal lymph nodes from patients with T1, N0, M0 pulmonary adenocarcinomas. Am J Surg Pathol. 2000;24:274-9.

13. Bonavina L, Ferrero S, Midolo V, Buffa R, Cesana B, Peracchia A. Lymph node micrometastases in patients with adenocarcinoma of the esophagogastric junction. J Gastrointest Surg. 1999;3:468-76.

14. Blaheta HJ, Schittek B, Breuninger H, et al. Lymph node micrometastases of cutaneous melanoma: increased sensitivity of molecular diagnosis in comparison to immunohistochemistry. Int $J$ Cancer. 1998;79:318-23.

15. Dowlatshahi K, Fan M, Snider HC, Habib FA. Lymph node micrometastases from breast carcinoma: reviewing the dilemma. Cancer. 1997;80:1188-97.

16. Adell G, Boeryd B, Franlund B, Sjodahl R, Hakansson L. Occurrence and prognostic importance of micrometastases in regional lymph nodes in Dukes' B colorectal carcinoma: an immunohistochemical study. Eur J Surg. 1996;162:637-42.

17. Moul JW, Lewis DJ, Ross AA, Kahn DG, Ho CK, McLeod DG. Immunohistologic detection of prostate cancer pelvic lymph node micrometastases: correlation to preoperative serum prostate-specific antigen. Urology. 1994;43:68-73.

18. Salerno CT, Frizelle S, Niehans GA, et al. Detection of occult micrometastases in non-small cell lung carcinoma by reverse transcriptasepolymerase chain reaction. Chest. 1998;113:1526-32.

19. Cote RJ, Peterson HF, Chaiwun B, et al. Role of immunohistochemical detection of lymph-node metastases in management of breast cancer. International Breast Cancer Study Group. Lancet. 1999;354:896-900.

20. Pantel K, Cote RJ, Fodstad O. Detection and clinical importance of micrometastatic disease. J Natl Cancer Inst. 1999;91:1113-24.

21. Chaiwun B, Saad A, Chatterjee SJ, Taylor CR, Beattie EJ, Cote RJ. Advances in the pathologic staging of lung cancer: detection of regional and systemic occult metastases. Pathology. 1996;4:155-68.

22. Cote RJ, Beattie EJ, Chaiwun B, et al. Detection of occult bone marrow micrometastases in patients with operable lung carcinoma. Ann Surg. 1995;222:415-23.

23. Qubain SW, Natsugoe S, Matsumoto M, Nakashima S, Baba M, Takao $\mathrm{S}$, et al. Micrometastases in the cervical lymph nodes in esophageal squamous cell carcinoma. Dis Esophagus. 2001;14:143-8.

24. Koduri PR. Sentinel lymph node micrometastases in DCIS. Ann Surg Oncol. 2001;8:380. 
25. Morgagni P, Saragoni L, Folli S, et al. Lymph node micrometastases in patients with early gastric cancer: experience with 139 patients. Ann Surg Oncol. 2001;8:170-4.

26. Bozzetti F, Andreola S, Bignami P, Sirizzotti G. Prognostic effects of lymph node micrometastases in patients undergoing curative gastrectomy for cancer. Tumori. 2000;86:470-1.

27. Yeatman TJ, Cox CE. The significance of breast cancer lymph node micrometastases (Review). Surg Oncol Clin N Am. 1999;8:481-96.

28. Cutait R, Alves VA, Lopes LC, et al. Restaging of colorectal cancer based on the identification of lymph node micrometastases through immunoperoxidase staining of CEA and cytokeratins. Dis Colon Rectum. 1991;34:917-20.

29. Noguchi S, Aihara T, Motomura K, Inaji H, Imaoka S, Koyama H. Histologic characteristics of breast cancers with occult lymph node metastases detected by keratin 19 mRNA reverse transcriptase-polymerase chain reaction. Cancer. 1996;78:1235-40.

30. Izbicki JR, Thetter O, Habekost M, et al. Radical systematic medias- tinal lymphadenectomy in non-small cell lung cancer: a randomized controlled trial. Br J Surg. 1994;81:229-35.

31. Kubuschok B, Passlick B, Izbicki JR, Thetter O, Pantel K. Disseminated tumor cells in lymph nodes as a determinant for survival in surgically resected non-small-cell lung cancer. J Clin Oncol. 1999;17:19-24.

32. Passlick B, Izbicki JR, Kubuschok B, Thetter O, Pantel K. Detection of disseminated lung cancer cells in lymph nodes: impact on staging and prognosis. Ann Thorac Surg. 1996;61:177-82.

33. D'Amico TA. Molecular biologic substaging of non-small cell lung cancer. J Thorac Cardiovasc Surg. 2002;123:409-10.

34. D'Amico TA, Aloia TA, Moore MB, et al. Predicting the sites of metastases from lung cancer using molecular biologic markers. Ann Thorac Surg. 2001;72:1144-8.

35. Ahrendt SA, Yang SC, Wu L, et al. Molecular assessment of lymph nodes in patients with resected stage I non-small cell lung cancer: preliminary results of a prospective study. J Thorac Cardiovasc Surg. 2002;123:466-73 